\title{
Pediatric neurosurgeons' views regarding prenatal surgery for myelomeningocele and the management of hydrocephalus: a national survey
}

\author{
John S. Riley, MD, MS, ${ }^{1}$ Ryan M. Antiel, MD, MS, ${ }^{2}$ Alan W. Flake, MD, ${ }^{3,4}$ Mark P. Johnson, MD, ${ }^{3,4}$ \\ Natalie E. Rintoul, MD, ${ }^{3,4}$ John D. Lantos, MD, ${ }^{5}$ Michael D. Traynor Jr., MD, ${ }^{2}$ N. Scott Adzick, MD,, 3 \\ Chris Feudtner, MD, PhD, MPH, ${ }^{3}$ and Gregory G. Heuer, MD, PhD $3,4,6$ \\ ${ }^{1}$ Department of Surgery, Hospital of the University of Pennsylvania, Philadelphia, Pennsylvania; ${ }^{2}$ Department of Surgery, Mayo \\ Clinic, Rochester, Minnesota; ${ }^{3}$ University of Pennsylvania Perelman School of Medicine and Children's Hospital of Philadelphia, \\ Pennsylvania; ${ }^{4}$ The Center for Fetal Diagnosis and Treatment, Children's Hospital of Philadelphia, Pennsylvania; ${ }^{5}$ Department of \\ Pediatrics, Children's Mercy Hospital, Kansas City, Missouri; and ${ }^{6}$ Division of Neurosurgery, Children's Hospital of Philadelphia, \\ Pennsylvania
}

OBJECTIVE The Management of Myelomeningocele Study (MOMS) compared prenatal with postnatal surgery for myelomeningocele (MMC). The present study sought to determine how MOMS influenced the clinical recommendations of pediatric neurosurgeons, how surgeons' risk tolerance affected their views, how their views compare to those of their colleagues in other specialties, and how their management of hydrocephalus compares to the guidelines used in the MOMS trial.

METHODS A cross-sectional survey was sent to all 154 pediatric neurosurgeons in the American Society of Pediatric Neurosurgeons. The effect of surgeons' risk tolerance on opinions and counseling of prenatal closure was determined by using ordered logistic regression.

RESULTS Compared to postnatal closure, $71 \%$ of responding pediatric neurosurgeons viewed prenatal closure as either "very favorable" or "somewhat favorable," and 51\% reported being more likely to recommend prenatal surgery in light of MOMS. Compared to pediatric surgeons, neonatologists, and maternal-fetal medicine specialists, pediatric neurosurgeons viewed prenatal MMC repair less favorably $(p<0.001)$. Responders who believed the surgical risks were high were less likely to view prenatal surgery favorably and were also less likely to recommend prenatal surgery $(p<$ 0.001). The management of hydrocephalus was variable, with $60 \%$ of responders using endoscopic third ventriculostomy in addition to ventriculoperitoneal shunts.

CONCLUSIONS The majority of pediatric neurosurgeons have a favorable view of prenatal surgery for MMC following MOMS, although less so than in other specialties. The reported acceptability of surgical risks was strongly predictive of prenatal counseling. Variation in the management of hydrocephalus may impact outcomes following prenatal closure.

https://thejns.org/doi/abs/10.3171/2019.7.FOCUS19406

KEYWORDS fetal surgery; myelomeningocele; spina bifida; hydrocephalus; MOMS trial; The Management of Myelomeningocele Study

$\mathrm{M}$ YELOMENINGOCELE (MMC) is characterized by protrusion of the spinal cord through the open vertebrae into the amniotic fluid, resulting in variable degrees of postnatal disability including impaired walking, neurogenic bladder, and hydrocephalus requiring the placement of a ventriculoperitoneal (VP) shunt. Prenatal surgery for MMC aims to mitigate spinal cord damage from the chemical and mechanical insults that occur in utero, and early results from nonrandomized studies suggested that this approach could minimize or reverse hind-

ABBREVIATIONS ASPN = American Society of Pediatric Neurosurgeons; ETV = endoscopic third ventriculostomy; MFM = maternal-fetal medicine; MMC = myelomeningocele; MOMS = The Management of Myelomeningocele Study; VP = ventriculoperitoneal. ACCOMPANYING EDITORIAL DOI: 10.3171/2019.8.FOCUS19641.

SUBMITTED May 26, 2019. ACCEPTED July 18, 2019.

INCLUDE WHEN CITING DOI: 10.3171/2019.7.FOCUS19406. 
brain herniation and decrease the need for VP shunting after birth. $1,8,24,34,35$ The Management of Myelomeningocele Study (MOMS) demonstrated that prenatal compared to postnatal closure resulted in a decrease in VP shunt placement ( $40 \%$ vs $82 \%$ ) and a decrease in the presence of hindbrain herniation (64\% vs $96 \%$ ), as well as an increase in the ability to walk independently without orthotics at 30 months of age ( $42 \%$ vs $21 \%)^{2}{ }^{2}$ There were, however, significant maternal and fetal risks. The prenatal surgery group experienced an increased incidence of chorioamniotic membrane separation (26\% vs $0 \%$ ), spontaneous membrane rupture (46\% vs $8 \%$ ), need for blood transfusion at cesarean delivery ( $9 \%$ vs $1 \%$ ), and area of uterine dehiscence at hysterotomy (10\% vs $0 \%$ ). These complications led to a greater incidence of prematurity (delivery at less than 30 weeks gestation) in the prenatal surgery group $(13 \%$ vs $0 \%)$.

Given that one of the principal advantages of prenatal surgery for MMC as determined by MOMS is the decreased need for a VP shunt, pediatric neurosurgeons' practices regarding the management of hydrocephalus are important to consider when evaluating the benefit derived from prenatal versus postnatal closure. These include the criteria used for intervention as well as the preferred treatment modality (VP shunt vs endoscopic third ventriculostomy [ETV]). A recent review of the MOMS data demonstrated that although only 4 patients in the study had shunts placed without meeting the trial criteria for shunt placement, 37 patients did not have shunts placed despite meeting criteria, suggesting that the original criteria used in the trial were more stringent than criteria actually used in clinical practice ${ }^{36}$ Furthermore, ETV has been increasingly used as an alternative treatment for MMC-associated hydrocephalus, ${ }^{19,33}$ and the differences in the criteria used for the two modalities may also be contributing to this observed trend. In an effort to remain in step with evolving practices in the management of hydrocephalus, therefore, the original MOMS trial criteria for shunt placement have been recently modified, emphasizing physical signs of hydrocephalus (i.e., bulging fontanelle, split sutures, or sunsetting eyes) over simply using an increase in head circumference for age or biventricular diameter alone. Although reanalysis of the MOMS results using these revised criteria showed an enduring benefit of prenatal closure ${ }^{36}$ it is unclear whether these revised criteria are concordant with current clinical practice among pediatric neurosurgeons generally or whether they reflect only the management of the smaller subset of patients with MMC enrolled in the MOMS trial.

Given the tradeoffs between the potential neonatal benefits and the maternal and neonatal risks, as well as evolving practice patterns in the management of postnatal hydrocephalus, prenatal surgery for MMC remains controversial. ${ }^{31}$ We have previously reported specialty-based variation in the interpretation of the MOMS results and their application to clinical practice among maternal-fetal medicine (MFM) specialists, neonatologists, and pediatric surgeons. ${ }^{4-6}$ In the present study, we sought to determine how MOMS has influenced the opinions and potential recommendations of pediatric neurosurgeons, how their views compared to those of other specialties involved in the management of MMC, how risk tolerance might impact their views, and how their practice patterns for the management of hydrocephalus compare to those used for the MOMS trial.

\section{Methods}

\section{Study Participants and Data Collection}

In the spring of 2017, we mailed a confidential, selfadministered, 9-page, 19-item questionnaire titled "Prenatal Surgery for Spina Bifida" to all 154 active pediatric neurosurgeons in the American Society of Pediatric Neurosurgeons (ASPN). The questionnaire used in this study represented an abridged version of the 32-item questionnaire previously used to sample 400 MFM specialists, 400 neonatologists, and 400 pediatric surgeons randomly selected from member lists of the Society for Maternal-Fetal Medicine, the American Academy of Pediatrics Section on Perinatal Pediatrics, and the American Academy of Pediatrics Section on Surgery, respectively. ${ }^{4-6}$ This study was reviewed and deemed exempt by the Mayo Clinic Institutional Review Board.

\section{Survey Instrument}

We reviewed the literature, consulted with content experts, conducted physician interviews at 5 maternal-fetal centers, formulated questions, and then conducted cognitive interviews in which draft survey instruments were administered to specialty colleagues whose feedback was used to revise questions further. The primary outcome variables were physicians' responses to a series of questions asked after participants reviewed a table of results from the MOMS trial (see Appendix A). First, physicians were asked, "In your opinion, how favorable is prenatal surgery for MMC, compared to postnatal surgery?" Response categories were "very favorable," "somewhat favorable," "somewhat unfavorable," "unfavorable," or "not sure." Next, physicians were asked, "In light of these results, please tell us whether your attitude changed regarding any of the options that are available to pregnant women with a newly diagnosed fetal MMC. Do these results make you more or less likely to recommend: termination of pregnancy, open uterine prenatal surgery, and postnatal repair (no fetal surgery)." Response categories for each were "less likely," "no change," and "more likely."

Given that the results of the MOMS trial may not be reproducible in some centers, we asked physicians to assume that their center offered prenatal surgery and that they were reviewing their institution's 5-year outcome data. We then asked physicians to indicate the highest complication rate associated with prenatal surgery that they would consider acceptable including: rate of perinatal mortality, rate of prematurity (less than 30 weeks), and rate of uterine dehiscence.

In addition to the questions about risk tolerance, favorability of the procedure, and counseling practices (identical to those asked of the other specialists), we also asked several questions unique to pediatric neurosurgeons. These included whether, why, and how the responder performed ETV in addition to VP shunts; preclosure imaging modalities used; and criteria used for ETV/VP shunt 
placement during and after postnatal closure. We also examined surgeons' demographic characteristics (age, sex, region, specialty, and years in practice) and practice setting type.

\section{Statistical Analysis}

Responses were deidentified, aggregated, and imported into Stata, version 14.2 (StataCorp). We used the American Association for Public Opinion Research RR2 response rate definition. ${ }^{3}$ A 1-sample t-test was used to compare acceptable risk rates to actual complication rates in the MOMS trial. Pediatric neurosurgeons' views regarding risk tolerance, the favorability of prenatal closure, and prenatal counseling practices were compared to those of other specialties involved in the treatment of MMC by using the Kruskal-Wallis test (with ties). Ordered logistic regression was used to determine the effect of personal characteristics, professional characteristics, and risk tolerance on opinions and counseling regarding prenatal closure. With respect to risk tolerance, responders were assigned a risk-aversion score ranging from 0 to 3, where a higher score indicated that the responder was more risk averse and a lower score indicated that the responder was less risk averse. A point was given for each instance in which the self-reported acceptable complication rate was less than the rate reported in the MOMS trial for perinatal death (MOMS trial rate: 3\%), uterine dehiscence (MOMS trial rate: $10 \%$ ), and premature delivery (MOMS trial rate: $13 \%){ }^{1}$

In this study, as well as in our previous study of MFMs, neonatologists, and pediatric surgeons, ${ }^{4-6}$ we used the complication rates reported in the first MOMS publication based on 158 of 183 patients (see Appendix A). ${ }^{2}$ The incidence of premature delivery in the full MOMS cohort, 183 patients, was later reported at $11 \% .{ }^{17}$ All statistical tests were 2 -sided, with an alpha level set at 0.05 for statistical significance.

\section{Results}

Of the 154 survey recipients, 100 (65\%) responded. The personal and professional characteristics of the responders are reported in Table 1.

\section{Interpretation of Evidence and Influence on Clinical Recommendations}

The majority $(71 \%)$ of pediatric neurosurgeons perceive prenatal surgery for MMC to be "somewhat favorable" or "very favorable," whereas $16 \%$ perceive it to be "somewhat unfavorable" or "unfavorable" (Table 2). This distribution of responses was found to be significantly different from those of similarly surveyed pediatric surgeons, neonatologists, and MFM specialists, of whom 93\% perceive the procedure to be "somewhat favorable" or "very favorable" ( $p<0.001)$. In light of MOMS, half $(51 \%)$ of pediatric neurosurgeons were "more likely" to recommend prenatal closure (Table 2). This was also significantly lower than the other specialists, of whom $69 \%$ were more likely to recommend the procedure $(p<0.001)$. MOMS had no effect on the majority of pediatric neurosurgeons with respect to their likelihood of recommending termi-
TABLE 1. Characteristics of the 100 US pediatric neurosurgeons who responded to the survey

\begin{tabular}{|c|c|}
\hline Characteristic & $\begin{array}{l}\text { Responses/No. } \\
\text { Responding (\%) }\end{array}$ \\
\hline Female sex & $13 / 97(13)$ \\
\hline \multicolumn{2}{|l|}{ Age } \\
\hline$<50$ yrs & $26 / 100(26)$ \\
\hline$\geq 50$ yrs & $74 / 100(74)$ \\
\hline Yrs in practice, mean \pm SD & $20 \pm 7$ \\
\hline \multicolumn{2}{|l|}{ Race or ethnic group } \\
\hline White or Caucasian & $83 / 100(83)$ \\
\hline Asian & $7 / 100(7)$ \\
\hline Black or African American & $2 / 100(2)$ \\
\hline Other & $8 / 100(8)$ \\
\hline \multicolumn{2}{|l|}{ Practice setting type } \\
\hline Solo, private & 1/99 (1) \\
\hline Group, private & $9 / 99(9)$ \\
\hline Institutional, private & $9 / 99(9)$ \\
\hline Academic & $75 / 99(76)$ \\
\hline Other & $5 / 99(5)$ \\
\hline Affiliation with fetal center & $71 / 100(71)$ \\
\hline \multicolumn{2}{|l|}{ Location-fetal care affiliates only } \\
\hline General hospital & $14 / 71(20)$ \\
\hline Women's/women and infants hospital & $23 / 71(32)$ \\
\hline Children's hospital & $40 / 71(56)$ \\
\hline Free-standing clinic or outpatient facility & $1 / 71(1)$ \\
\hline Other & $3 / 71(4)$ \\
\hline $\begin{array}{l}\text { Counseled a pregnant woman with a newly } \\
\text { diagnosed fetal MMC in the past } 12 \text { mos }\end{array}$ & $83 / 100(83)$ \\
\hline
\end{tabular}

Percentages may not total 100 because of rounding and/or multiple responses.

nation of pregnancy or postnatal closure, with $86 \%$ and $70 \%$ of responders reporting "no change" for these survey items, respectively.

\section{Risk Tolerance}

Pediatric neurosurgeons were next asked to report the highest complication rates they would consider acceptable for prenatal surgery (Table 3). On average, responders would tolerate a $4 \%$ rate of perinatal death, a $12 \%$ rate of prematurity (delivery at less than 30 weeks), and an $8.1 \%$ rate of uterine dehiscence. These were similar to the actual rates reported in the MOMS trial (3\% perinatal mortality, $13 \%$ prematurity, and $10 \%$ uterine dehiscence). Only the acceptable rate of uterine dehiscence was significantly different from the reported rate $(8.1 \%$ vs $10 \%, \mathrm{p}=0.02)$; the acceptable rates of perinatal death and prematurity did not differ significantly ( $4.0 \%$ vs $3 \%, \mathrm{p}=0.052$ and $12.0 \%$ vs $13 \%, \mathrm{p}=0.42$, respectively). Compared to other specialists involved in the care of these patients, pediatric neurosurgeons were significantly more risk averse (Table 3); their acceptable rates of perinatal death, prematurity, and uterine dehiscence were significantly lower on average ( $\mathrm{p}$ $<0.001, \mathrm{p}<0.001$, and $\mathrm{p}=0.025$, respectively). 
TABLE 2. Pediatric neurosurgeon opinions about the MOMS results compared to other specialists

\begin{tabular}{|c|c|c|c|}
\hline \multirow[b]{2}{*}{ Survey Item } & \multicolumn{2}{|c|}{ No. $(\%)$} & \multirow[b]{2}{*}{ p Value } \\
\hline & Pediatric Neurosurgeons & Other Specialists & \\
\hline \multicolumn{4}{|l|}{ Considering the known risks and benefits: } \\
\hline How favorable is open prenatal surgery for MMC? & & & $<0.001$ \\
\hline Very favorable & $9(10)$ & $219(33)$ & \\
\hline Somewhat favorable & $55(61)$ & $398(60)$ & \\
\hline Not sure & $12(13)$ & $12(2)$ & \\
\hline Somewhat unfavorable & $9(10)$ & $25(4)$ & \\
\hline Unfavorable & $5(6)$ & $7(1)$ & \\
\hline \multicolumn{4}{|c|}{ Compared to before the MOMS trial, are you now more or less likely to recommend: } \\
\hline Termination of pregnancy & & & 0.004 \\
\hline Less likely & $11(13)$ & $182(28)$ & \\
\hline No change & $74(86)$ & $468(71)$ & \\
\hline More likely & $1(1)$ & $8(1)$ & \\
\hline Prenatal MMC closure & & & $<0.001$ \\
\hline Less likely & $7(8)$ & $23(3)$ & \\
\hline No change & $38(42)$ & $185(28)$ & \\
\hline More likely & $46(51)$ & $454(69)$ & \\
\hline Postnatal MMC closure (no fetal surgery) & & & $<0.001$ \\
\hline Less likely & $17(19)$ & $250(38)$ & \\
\hline No change & $62(70)$ & $382(58)$ & \\
\hline More likely & $10(11)$ & $25(4)$ & \\
\hline
\end{tabular}

Values are expressed as the number of respondents (\%), although the denominators vary because of missing responses, and percentages may not total 100 because of rounding. Boldface type indicates statistical significance.

${ }^{*} p$ values are for the comparison between pediatric neurosurgeons and other specialists and were calculated using the Kruskal-Wallis test (with ties).

\section{Factors Affecting Opinions and Clinical Recommendations}

Personal characteristics, professional characteristics, and risk tolerance were assessed to determine what effect, if any, they had on responders' opinions regarding prenatal closure of MMC. No correlation was found between a responder's opinion of prenatal closure and their sex $(\mathrm{p}=$
0.8 ); age (age $<50$ vs $\geq 50$ years, $\mathrm{p}=0.12$ ); age (continuous variable, $\mathrm{p}=0.07$ ); or race (white vs nonwhite, $\mathrm{p}=$ $0.12)$. Neither was there a significant correlation with their years in practice $(\mathrm{p}=0.12)$; practice type (academic vs nonacademic, $p=0.87$ ); or affiliation with a fetal center $(p=0.27)$. By contrast, there was a strong correlation between a responder's tolerance for risk and their opinion

TABLE 3. Pediatric neurosurgeon risk tolerance compared to other specialists

\begin{tabular}{|c|c|c|c|c|}
\hline \multirow[b]{2}{*}{ Survey Item } & \multirow[b]{2}{*}{ MOMS Trial } & \multicolumn{2}{|c|}{ Group } & \multirow[b]{2}{*}{ p Value* } \\
\hline & & Pediatric Neurosurgeons & Other Specialists & \\
\hline \multicolumn{5}{|l|}{$\begin{array}{l}\text { What is the highest complication rate associated with open } \\
\text { prenatal surgery that you would consider acceptable: }\end{array}$} \\
\hline Rate of perinatal death, percentage & & & & $<0.001$ \\
\hline Mean (SD) & 3 & $4.0(4.5)$ & $6.6(8.6)$ & \\
\hline Median (IQR) & & $3(2-5)$ & $5(3-5)$ & \\
\hline Rate of prematurity less than 30 weeks, percentage & & & & $<0.001$ \\
\hline Mean (SD) & 13 & $12.0(11.8)$ & $16.8(11.0)$ & \\
\hline Median (IQR) & & $10(5-15)$ & $15(10-20)$ & \\
\hline Rate of uterine dehiscence, percentage & & & & 0.025 \\
\hline Mean (SD) & 10 & $8.1(7.5)$ & $9.4(8.1)$ & \\
\hline Median (IQR) & & $5(2-10)$ & $10(5-10)$ & \\
\hline
\end{tabular}

$\mathrm{IQR}=$ interquartile range.

Boldface type indicates statistical significance.

${ }^{*} p$ values are for the comparison between pediatric neurosurgeons and other specialists and were calculated using the Kruskal-Wallis test (with ties). 
TABLE 4. Pediatric neurosurgeon opinions concerning the management of hydrocephalus

\begin{tabular}{|c|c|}
\hline Survey Item & Responses/No. Responding (\%)* \\
\hline \multicolumn{2}{|l|}{$\begin{array}{l}\text { Do you perform endoscopic third ventriculostomies (with or without choroid plexus cauterization) on } \\
\text { infants and children with spina bifida and hydrocephalus? }\end{array}$} \\
\hline Yes & $60 / 100(60)$ \\
\hline No & $40 / 100(40)$ \\
\hline \multicolumn{2}{|l|}{$\begin{array}{l}\text { If yes, estimate the percentage of infants and children with spina bifida and hydrocephalus that you } \\
\text { perform an endoscopic third ventriculostomy for hydrocephalus: }\end{array}$} \\
\hline Mean (SD) & $27(28)$ \\
\hline Median (IQR) & $15(10-30)$ \\
\hline \multicolumn{2}{|l|}{ If you perform shunts but not endoscopic third ventriculostomies, is it because: } \\
\hline The failure rate of endoscopic third ventriculostomy is too high compared to shunt & $32 / 40(80)$ \\
\hline The procedure has greater surgical risk than VP shunt and is unwarranted & $11 / 40(28)$ \\
\hline I have little or no experience with the procedure & $6 / 40(15)$ \\
\hline \multicolumn{2}{|l|}{ If you perform endoscopic third ventriculostomies, do you (choose one): } \\
\hline Only open the floor of the third ventricle & $23 / 60(38)$ \\
\hline Perform with septostomy and choroid plexus cauterization & $33 / 60(55)$ \\
\hline Perform with unilateral choroid plexus cauterization & $3 / 60(5)$ \\
\hline Not applicable & $1 / 60(2)$ \\
\hline \multicolumn{2}{|l|}{ If you perform endoscopic third ventriculostomies, do you (choose one): } \\
\hline Make every attempt to cauterize all visible choroid plexus & $24 / 59(41)$ \\
\hline Cauterize more than $90 \%$ & $8 / 59(14)$ \\
\hline Cauterize at least $50 \%$ & $6 / 59(10)$ \\
\hline The amount of choroid plexus cauterized does not matter & $7 / 59(12)$ \\
\hline Not applicable & $14 / 59(24)$ \\
\hline \multicolumn{2}{|l|}{ For infants with spina bifida, what pre-closure imaging do you obtain (select all that apply): } \\
\hline Ultrasound & $68 / 100(68)$ \\
\hline CT scan & $8 / 100(8)$ \\
\hline MRI & $31 / 100(31)$ \\
\hline I do not routinely obtain pre-closure imaging & $8 / 100(8)$ \\
\hline \multicolumn{2}{|l|}{ When performing postnatal spina bifida closures, do you (choose one): } \\
\hline Place a shunt at the same time & $5 / 92(5)$ \\
\hline Perform endoscopic third ventriculostomies at the same time & $0 / 92(0)$ \\
\hline Place a shunt within 1-10 days of life if hydrocephalus is present & $60 / 92(65)$ \\
\hline Perform endoscopic third ventriculostomies within 1-10 days of life if hydrocephalus is present & $17 / 92(18)$ \\
\hline Do not place shunts or perform endoscopic third ventriculostomies within the first 10 days of life & $10 / 92(11)$ \\
\hline
\end{tabular}

Percentages may not equal 100 due to rounding and/or multiple responses.

* Unless otherwise indicated, values denote the number of responses per those responding (\%).

regarding the favorability of prenatal surgery for MMC, such that a higher risk-aversion score predicted a less favorable view of prenatal surgery $(\mathrm{OR}-0.89,95 \% \mathrm{CI}-1.37$ to $-0.41, \mathrm{p}<0.001$ ).

A similar analysis was then performed to explore the effects of these factors on a responder's likelihood of recommending prenatal closure. No correlation was found between a responder's sex $(\mathrm{p}=0.57)$; age (age $<50$ vs $\geq$ 50 years, $p=0.11$ ); or race (white vs nonwhite, $p=0.78$ ) and their likelihood of recommending prenatal closure. However, an association was found when using age as a continuous variable, with the likelihood of recommending prenatal closure decreasing with age (OR $-0.069,95 \%$ $\mathrm{CI}-0.13$ to $-0.0051, \mathrm{p}=0.034)$. No significant correlation was found with years in practice $(\mathrm{p}=0.062)$, practice type ( $p=0.89)$, or affiliation with a fetal center $(p=0.15)$. There was a strong correlation between a responder's risk tolerance and their likelihood of recommending prenatal closure, such that a higher risk-aversion score predicted a lower likelihood of recommending prenatal closure (OR $-1.12,95 \%$ CI -1.67 to $-0.57, \mathrm{p}<0.001)$.

\section{Management of Hydrocephalus and Shunt Criteria}

Pediatric neurosurgeons' opinions regarding the management of hydrocephalus are presented in Table 4. A majority (60\%) of responders perform ETV in addition to VP shunts, and they estimated that on average they use this technique to treat hydrocephalus in $27 \%$ of cases. The most common intraoperative approach reported (55\%) was 


\begin{tabular}{|c|c|c|c|c|}
\hline \multirow[b]{2}{*}{ Survey Item } & \multicolumn{4}{|c|}{ Responses/No. Responding (\%) } \\
\hline & $\begin{array}{l}\text { Definitely } \\
\text { Would Not } \\
\text { Recommend }\end{array}$ & $\begin{array}{l}\text { Probably } \\
\text { Would Not } \\
\text { Recommend }\end{array}$ & $\begin{array}{l}\text { Probably } \\
\text { Would } \\
\text { Recommend }\end{array}$ & $\begin{array}{l}\text { Definitely } \\
\text { Would } \\
\text { Recommend }\end{array}$ \\
\hline \multicolumn{5}{|l|}{$\begin{array}{l}\text { Would you perform either a shunt or an endoscopic third ventriculostomy for hydrocephalus } \\
\text { in the following clinical scenarios? Assume that other signs/symptoms are absent if not } \\
\text { listed: }\end{array}$} \\
\hline \multicolumn{5}{|l|}{ Meets criteria } \\
\hline $\begin{array}{l}\text { Bulging fontanelle or split sutures or sunsetting eyes with at least } 1 \text { of the following: } \\
\text { Head circumference with growth rate beyond expected on growth chart } \\
\text { Increasing hydrocephalus on consecutive imaging } \\
\text { Head circumference greater than } 95 \%\end{array}$ & $1 / 96(1)$ & $0 / 96(0)$ & $14 / 96(15)$ & $81 / 96(84)$ \\
\hline Ventriculomegaly on imaging and large syringomelia (syrinx) & $3 / 99(3)$ & $3 / 99(3)$ & $41 / 99$ (41) & $52 / 99(53)$ \\
\hline $\begin{array}{l}\text { Ventriculomegaly on imaging and stridor, swallowing difficulties, apnea, or brady- } \\
\text { cardia }\end{array}$ & $1 / 99(1)$ & $2 / 99(2)$ & $14 / 99(14)$ & $82 / 99(83)$ \\
\hline Persistent cerebrospinal fluid (CSF) leak or bulge at back repair site & 1/98 (1) & $2 / 98(2)$ & $33 / 98(34)$ & $62 / 98(63)$ \\
\hline \multicolumn{5}{|l|}{ Does not meet criteria } \\
\hline $\begin{array}{l}\text { Increase in head circumference beyond expected on growth chart (crossing } \\
\text { percentiles) }\end{array}$ & $1 / 100(1)$ & $27 / 100(27)$ & $62 / 100(62)$ & $10 / 100(10)$ \\
\hline $\begin{array}{l}\text { Increasing hydrocephalus on consecutive imaging (increasing ratio of biventricular } \\
\text { to biparietal diameter) }\end{array}$ & $0 / 99(0)$ & $10 / 99(10)$ & $67 / 99(68)$ & $22 / 99(22)$ \\
\hline Head circumference greater than $95 \%$ for gestational age & $6 / 96(6)$ & $58 / 96(60)$ & $28 / 96(29)$ & $4 / 96(4)$ \\
\hline
\end{tabular}

Percentages may not equal 100 due to rounding.

to perform a septostomy and choroid plexus cauterization, although there was no consensus as to the amount of choroid plexus that needed to be cauterized. Responders not performing ETV do not perform it mainly because of the higher failure rate of ETV compared to VP shunts. Prior to postnatal MMC, the most commonly obtained imaging modality is ultrasound (68\%). A majority $(65 \%)$ of responders place a VP shunt within 1-10 days of postnatal closure if hydrocephalus is present.

In order to determine if the modified shunt criteria for the MOMS trial are consistent with current practice among pediatric neurosurgeons, those surveyed were asked if they would perform either a VP shunt or an ETV for hydrocephalus in a number of clinical scenarios, some of which met the modified shunt criteria and others of which did not. Aggregated results are presented in Table 5 . The overwhelming majority (94\%) of responders "probably" or "definitely" would recommend placement of a VP shunt or an ETV in a patient who meets the modified shunt criteria. However, $90 \%$ of responders would also "probably" or "definitely" recommend placement of a VP shunt or an ETV in a patient who does not meet modified shunt criteria; i.e., a patient with imaging evidence of progressive hydrocephalus in the absence of physical signs of hydrocephalus (bulging fontanelle, split sutures, or sunsetting eyes).

\section{Discussion}

This study sought to determine how MOMS influenced the opinions and clinical recommendations of pediatric neurosurgeons, how their views compare to those of their colleagues in other specialties, how risk tolerance might impact their views, and how their management of hydrocephalus compares to the revised guidelines used in the MOMS trial. To accomplish this, we surveyed all pediatric neurosurgeons from the ASPN, achieving a 65\% response rate. The majority of the 100 responders viewed prenatal closure as either "very favorable" or "somewhat favorable," and half of responders reported being more likely to recommend prenatal surgery in light of MOMS. Compared to similarly surveyed pediatric surgeons, neonatologists, and MFM specialists, pediatric neurosurgeons viewed prenatal closure less favorably. Responders accepting risks below those reported in the MOMS trial were less likely to view prenatal surgery favorably and less likely to recommend prenatal surgery. The management of hydrocephalus was heterogeneous, with $60 \%$ of responders using ETV in addition to VP shunts. Finally, although nearly all responders agree that the modified shunt criteria warrant intervention, the vast majority would definitely or probably intervene for an increase in hydrocephalus or head circumference in isolation.

The differences between pediatric neurosurgeons and other specialists with respect to their opinions of prenatal closure and counseling practices were a notable finding of this study. Numerous publications have demonstrated that marked differences can exist between specialties with respect to their interpretation of trial results, particularly in complex, controversial, or novel areas of clinical practice. . $1,16,18,21-23,29,32$ Among the plausible explanations for this are specialty-specific concerns regarding the validity or paucity of trial data, bias toward one's scope of practice or expertise, and variation in the relative importance as- 
cribed to certain outcomes..$^{13,28,30}$ This study reveals both a strong association between unfavorable opinions and risk aversion among pediatric neurosurgeons as well as a significantly lower tolerance for risk of fetal death, maternal dehiscence, and prematurity among pediatric neurosurgeons compared to their colleagues in other specialties. These results suggest that pediatric surgeons weigh the reported risks and benefits of prenatal closure differently than their peers.

There are several potential explanations why this may be the case. First, pediatric neurosurgeons tend to follow these patients long term, with special emphasis on neurological outcomes and complications. Compared to other specialists whose care for these patients is limited to the perinatal period, they may therefore ascribe greater weight to some of the longer-term sequelae of MMC for which prenatal closure has not shown clear benefit. For example, with respect to neurogenic bladder, whereas MOMS demonstrated that prenatal closure was associated with improvement in bladder trabeculation and a lower rate of open bladder neck, it did not significantly reduce the need for clean intermittent catheterization by 30 months of age. ${ }^{7}$ The potential benefit for urinary functional outcomes, especially at school age, remains controversial. ${ }^{9,11,15,20}$ Additionally, pediatric neurosurgeons treat other long-term sequelae of MMC repair, specifically the symptoms of tethered cords or the presence of inclusion cysts, which may be more prevalent in patients who undergo fetal surgery and therefore may influence pediatric neurosurgeons' opinions on prenatal closure.

Second, pediatric neurosurgeons may weigh the benefit of reduced need for VP shunts differently than their colleagues. As our survey results demonstrate, current practice among pediatric neurosurgeons with respect to the management of hydrocephalus is variable and controversial. Whereas ETV was not a widely adopted modality during MOMS enrollment (2003-2010), we found that ETV is currently used by a majority $(60 \%)$ of pediatric neurosurgeons as an alternative to VP shunting for some cases of hydrocephalus secondary to spina bifida. Furthermore, significant variability exists among adopters of this modality in the timing, frequency, and technique of the procedure. Given the increasing use of ETV to manage hydrocephalus following either prenatal or postnatal MMC repair as well as its characterization as a less invasive or burdensome procedure, ${ }^{12}$ a reduced rate of VP shunting may not be considered a concrete metric of benefit by all pediatric neurosurgeons.

Furthermore, there is no broad consensus among pediatric neurosurgeons regarding the criteria to intervene for hydrocephalus. ${ }^{10,27}$ Efforts by the MOMS investigators to achieve greater concordance between the criteria used for VP shunt placement in the MOMs trial and nationwide practice by emphasizing the physical signs of hydrocephalus have yielded criteria, our study shows, that on the one hand are widely regarded to be sufficient for intervention when met, yet on the other hand are not widely regarded to exclude intervention when not met: $90 \%$ of responders probably or definitely would intervene for a patient demonstrating increasing hydrocephalus on consecutive imaging in the absence of physical signs, which is contrary to the trends in shunt placement observed in a recent review of the MOMS patients. ${ }^{36}$ Awareness among pediatric neurosurgeons of the evolving and controversial nature of the surgical management of hydrocephalus, both in the criteria for and modality of intervention, may be a second factor contributing to the lower favorability scores reported by pediatric neurosurgeons compared to their peers in other specialties who are less familiar with these nuances.

With respect to the methods of this study, one strength is the response rate of $65 \%$ among all members of the ASPN. Given the relatively small number of dedicated pediatric neurosurgeons currently practicing in North America and the high incidence of ASPN membership among them, we are confident that we have achieved sufficient sampling of our population of interest to assert representation of their opinions generally. A second strength of this study is its novelty. To our knowledge, ours is the first and only study to report pediatric neurosurgeons' opinions regarding prenatal MMC repair, which is a persistently controversial, multidisciplinary area of clinical practice for which the opinions of this important group had been heretofore absent in the literature.

The limitations of our study are related to the design and reach of our survey. We did not solicit opinions about all areas of controversy related to prenatal closure, including how the MOMS results are communicated to the public and the generalizability of the results beyond the strict inclusion criteria of the trial. Additionally, we did not ask whether the responder performs prenatal surgery and with what frequency. As such, we may have failed to detect factors that contributed significantly to the observed differences of opinion.

We observed that younger pediatric neurosurgeons were more likely to recommend prenatal surgery in light of MOMS than their older colleagues. Importantly, however, only one responder completed their training in the post-MOMS era. Surveying pediatric neurosurgeons who recently took their boards and inquiring whether they trained at a Hydrocephalus Clinical Research Network center may have helped us better assess the impact of the evolving training environment on opinions of prenatal closure. Additionally, our study included only pediatric neurosurgeons practicing in North America. Given that prenatal closure of MMC is now performed at centers around the globe, ${ }^{25,26,37}$ the opinions of international pediatric neurosurgeons should be solicited in future studies.

Despite these limitations, this study indicates that the majority of pediatric neurosurgeons view the MOMS results favorably, revealing risk aversion to be a robust predictor of those with persistent reservations toward prenatal closure. Compared to their peers in pediatric surgery, neonatology, and MFM, however, pediatric neurosurgeons are less enthusiastic about prenatal closure. Finally, although broad consensus exists among pediatric neurosurgeons that the modified shunt criteria are sufficient indication to treat hydrocephalus following MMC repair, we found that surgeon-specific variations in practice persist, presenting challenges to achieving the greatest benefit from prenatal closure. The results of this study can be considered by professional societies as they draft practice guidelines, by researchers designing future studies on the outcomes of 
prenatal closure, and by individual physicians counseling patients in their clinical practice.

\section{Acknowledgments}

Research reported in this publication was supported by a grant from the Greenwall Foundation to Dr. Antiel and by the National Center for Advancing Translational Sciences of the NIH under award number TL1TR001880 to Dr. Riley. The content is solely the responsibility of the authors and does not necessarily represent the official views of the NIH.

\section{References}

1. Adzick NS, Sutton LN, Crombleholme TM, Flake AW: Successful fetal surgery for spina bifida. Lancet 352:1675-1676, 1998

2. Adzick NS, Thom EA, Spong CY, Brock JW III, Burrows PK, Johnson MP, et al: A randomized trial of prenatal versus postnatal repair of myelomeningocele. N Engl J Med 364:993-1004, 2011

3. American Association of Public Opinion Research: Standard Definitions: Final Dispositions of Case Codes and Outcome Rates for Surveys. Oakbrook Terrace, IL: AAPOR, 2015 (https://www.aapor.org/AAPOR_Main/ media/MainSiteFiles/Standard-Definitions2015_8thEd.pdf) [Accessed August 16, 2019]

4. Antiel RM, Collura CA, Flake AW, Johnson MP, Rintoul NE, Lantos JD, et al: Physician views regarding the benefits and burdens of prenatal surgery for myelomeningocele. J Perinatol 37:994-998, 2017

5. Antiel RM, Curlin FA, Lantos JD, Collura CA, Flake AW, Johnson MP, et al: Attitudes of paediatric and obstetric specialists towards prenatal surgery for lethal and non-lethal conditions. J Med Ethics 44:234-238, 2018

6. Antiel RM, Flake AW, Johnson MP, Khalek N, Rintoul NE, Lantos JD, et al: Specialty-based variation in applying maternal-fetal surgery trial evidence. Fetal Diagn Ther 42:210-217, 2017

7. Brock JW III, Carr MC, Adzick NS, Burrows PK, Thomas JC, Thom EA, et al: Bladder function after fetal surgery for myelomeningocele. Pediatrics 136:e906-e913, 2015

8. Bruner JP, Tulipan N, Paschall RL, Boehm FH, Walsh WF, Silva SR, et al: Fetal surgery for myelomeningocele and the incidence of shunt-dependent hydrocephalus. JAMA 282:1819-1825, 1999

9. Carr MC: Urological results after fetal myelomeningocele repair in pre-MOMS trial patients at the Children's Hospital of Philadelphia. Fetal Diagn Ther 37:211-218, 2015

10. Chakraborty A, Crimmins D, Hayward R, Thompson D: Toward reducing shunt placement rates in patients with myelomeningocele. J Neurosurg Pediatr 1:361-365, 2008

11. Clayton DB, Tanaka ST, Trusler L, Thomas JC, Pope JC IV, Adams MC, et al: Long-term urological impact of fetal myelomeningocele closure. J Urol 186 (4 Suppl):1581-1585, 2011

12. Elbabaa SK, Gildehaus AM, Pierson MJ, Albers JA, Vlastos EJ: First 60 fetal in-utero myelomeningocele repairs at Saint Louis Fetal Care Institute in the post-MOMS trial era: hydrocephalus treatment outcomes (endoscopic third ventriculostomy versus ventriculo-peritoneal shunt). Childs Nerv Syst 33:1157-1168, 2017

13. Ellerbeck EF, Jencks SF, Radford MJ, Kresowik TF, Craig AS, Gold JA, et al: Quality of care for Medicare patients with acute myocardial infarction. A four-state pilot study from the Cooperative Cardiovascular Project. JAMA 273:1509-1514, 1995

14. Goldman N: New evidence rekindles the hormone therapy debate. J Fam Plann Reprod Health Care 36:61-64, 2010

15. Horst M, Mazzone L, Schraner T, Bodmer C, Möhrlen U,
Meuli M, et al: Prenatal myelomeningocele repair: Do bladders better? Neurourol Urodyn 36:1651-1658, 2017

16. Jacobs WCH, van Tulder M, Arts M, Rubinstein SM, van Middelkoop M, Ostelo R, et al: Surgery versus conservative management of sciatica due to a lumbar herniated disc: a systematic review. Eur Spine J 20:513-522, 2011

17. Johnson MP, Bennett KA, Rand L, Burrows PK, Thom EA, Howell LJ, et al: The Management of Myelomeningocele Study: obstetrical outcomes and risk factors for obstetrical complications following prenatal surgery. Am J Obstet Gynecol 215:778.e1-778.e9, 2016

18. Kim SP, Gross CP, Nguyen PL, Smaldone MC, Thompson $\mathrm{RH}$, Shah ND, et al: Specialty bias in treatment recommendations and quality of life among radiation oncologists and urologists for localized prostate cancer. Prostate Cancer Prostatic Dis 17:163-169, 2014 (Erratum in Prostate Cancer Prostatic Dis 17:212, 2014)

19. Kulkarni AV, Riva-Cambrin J, Browd SR, Drake JM, Holubkov R, Kestle JRW, et al: Endoscopic third ventriculostomy and choroid plexus cauterization in infants with hydrocephalus: a retrospective Hydrocephalus Clinical Research Network study. J Neurosurg Pediatr 14:224-229, 2014

20. Lee NG, Gomez P, Uberoi V, Kokorowski PJ, Khoshbin S, Bauer SB, et al: In utero closure of myelomeningocele does not improve lower urinary tract function. J Urol 188 (4 Suppl):1567-1571, 2012

21. Lewis RA, Williams NH, Sutton AJ, Burton K, Din NU, Matar HE, et al: Comparative clinical effectiveness of management strategies for sciatica: systematic review and network meta-analyses. Spine J 15:1461-1477, 2015

22. Manson JE, Chlebowski RT, Stefanick ML, Aragaki AK, Rossouw JE, Prentice RL, et al: Menopausal hormone therapy and health outcomes during the intervention and extended poststopping phases of the Women's Health Initiative randomized trials. JAMA 310:1353-1368, 2013

23. Manson JE, Kaunitz AM: Menopause management-getting clinical care back on track. N Engl J Med 374:803-806, 2016

24. Meuli M, Meuli-Simmen C, Hutchins GM, Yingling CD, Hoffman KM, Harrison MR, et al: In utero surgery rescues neurological function at birth in sheep with spina bifida. Nat Med 1:342-347, 1995

25. Meuli M, Moehrlen U, Flake A, Ochsenbein N, Huesler M, Biro P, et al: Fetal surgery in Zurich: key features of our first open in utero repair of myelomeningocele. Eur J Pediatr Surg 23:494-498, 2013

26. Moron AF, Barbosa MM, Milani H, Sarmento SG, Santana E, Suriano IC, et al: Perinatal outcomes after open fetal surgery for myelomeningocele repair: a retrospective cohort study. BJOG 125:1280-1286, 2018

27. Norkett W, McLone DG, Bowman R: Current management strategies of hydrocephalus in the child with open spina bifida. Top Spinal Cord Inj Rehabil 22:241-246, 2016

28. Perez EA: Perceptions of prognosis, treatment, and treatment impact on prognosis in non-small cell lung cancer. Chest 114:593-604, 1998

29. Peul WC, van Houwelingen HC, van den Hout WB, Brand R, Eekhof JAH, Tans JTJ, et al: Surgery versus prolonged conservative treatment for sciatica. N Engl J Med 356:22452256, 2007

30. Seidman AD: Sequential single-agent chemotherapy for metastatic breast cancer: therapeutic nihilism or realism? J Clin Oncol 21:577-579, 2003

31. Simpson JL, Greene MF: Fetal surgery for myelomeningocele? N Engl J Med 364:1076-1077, 2011

32. Sommers BD, Beard CJ, D'Amico AV, Kaplan I, Richie JP, Zeckhauser RJ: Predictors of patient preferences and treatment choices for localized prostate cancer. Cancer 113:2058-2067, 2008 
33. Stone SSD, Warf BC: Combined endoscopic third ventriculostomy and choroid plexus cauterization as primary treatment for infant hydrocephalus: a prospective North American series. J Neurosurg Pediatr 14:439-446, 2014

34. Sutton LN, Adzick NS, Bilaniuk LT, Johnson MP, Crombleholme TM, Flake AW: Improvement in hindbrain herniation demonstrated by serial fetal magnetic resonance imaging following fetal surgery for myelomeningocele. JAMA 282:1826-1831, 1999

35. Tulipan N, Hernanz-Schulman M, Bruner JP: Reduced hindbrain herniation after intrauterine myelomeningocele repair: a report of four cases. Pediatr Neurosurg 29:274-278, 1998

36. Tulipan N, Wellons JC III, Thom EA, Gupta N, Sutton LN, Burrows PK, et al: Prenatal surgery for myelomeningocele and the need for cerebrospinal fluid shunt placement. J Neurosurg Pediatr 16:613-620, 2015

37. Zamłyński J, Olejek A, Koszutski T, Ziomek G, Horzelska E, Gajewska-Kucharek A, et al: Comparison of prenatal and postnatal treatments of spina bifida in Poland-a non-randomized, single-center study. J Matern Fetal Neonatal Med 27:1409-1417, 2014

\section{Disclosures}

The authors report no conflict of interest concerning the materials or methods used in this study or the findings specified in this paper.

\section{Author Contributions}

Conception and design: Heuer, Antiel, Flake, Johnson, Rintoul, Lantos, Feudtner. Acquisition of data: Antiel. Analysis and interpretation of data: Riley, Antiel, Lantos, Traynor, Feudtner. Drafting the article: Riley. Critically revising the article: Heuer, Riley, Antiel, Rintoul, Adzick, Feudtner. Reviewed submitted version of manuscript: all authors. Statistical analysis: Riley, Antiel, Feudtner. Study supervision: Heuer, Adzick, Feudtner. Presented the data at an international meeting: Traynor.

\section{Supplemental Information}

Online-Only Content

Supplemental material is available online.

Appendix A. https://thejns.org/doi/suppl/10.3171/2019.7. FOCUS19406.

\section{Correspondence}

Gregory G. Heuer: Children's Hospital of Philadelphia, PA. heuerg@email.chop.edu. 